\title{
Multisectorial changes in the ciliary muscle during accommodation measured with high-resolution optical coherence tomography
}

\section{Alterações multissetoriais no músculo ciliar durante a acomodação com uma tomografía de coerência óptica de alta resolução}

\author{
Daniel Monsálvez-Romín', Alberto Domínguez-Vicent', José. J. Esteve-Taboada', Robert Montés-Micó', \\ Teresa Ferrer-Blasco \\ 1. Department of Optics and Optometry and Vision Sciences. University of Valencia, Valencia, Spain.
}

\begin{abstract}
I Purpose: To measure changes in the anterior ciliary muscle during accommodation at the nasal, superior, temporal, and inferior sectors by means of an anterior chamber optical coherence tomographer, and correlate them with vergence changes. Methods: Twenty-four subjects with healthy, phakic eyes, whose mean age was $27.1 \pm 8.9$ years, underwent measurement with an anterior chamber optical coherence tomographer. The anterior ciliary muscle was measured at the nasal, temporal, superior, and inferior sectors for $0,-1,-2$, and $-3 \mathrm{D}$ of vergence. A linear model was used to assess the correlation of each eye parameter with the accommodative demand. Results: The anterior ciliary muscle area significantly increased with accommodation for each sector, with a maximum increase of about $30 \%$ for the nasal-temporal sectors and about $25 \%$ for the inferior-temporal sectors. The linear model showed a tendency toward a positive relationship between change in the ciliary muscle area of each sector and vergence. Conclusion: The anterior ciliary muscle area tends to increase with accommodation, although the increase has been shown to be symmetric between the pair sectors superior-nasal and inferior-temporal. These results may help to increase understanding of accommodation biometry and biomechanics.
\end{abstract}

Keywords: Accommodation, ocular; Biometry; Ciliary muscle; Tomography; Optical coherence; Presbyopia

\footnotetext{
Submitted for publication: February 27, 2018

Accepted for publication: October 17, 2018

Funding: This study was supported by the Ministerio de Economía y Competitivad (Research Project SAF2013-44510-R with FEDER Funds), a University of Valencia research scholarship (UV-INV-PREDOC13-110412) awarded to Alberto DomínguezVicent, and a Ministerio de Educación, Cultura y Deporte research scholarship (FPU13/05332) awarded to Daniel Monsálvez-Romín.

Disclosure of potential conflicts of interest: None of the authors have any potentia conflicts of interest to disclose.

Corresponding author: Alberto Domínguez-Vicent.

Department of Optics and Optometry and Visual Sciences, University of Valencia C/ Dr Moliner, 50 - 46100 - Burjassot - Spain - E-mail: alberto.vicent@uv.es

Approved by the following research ethics committee: Universitat de Valencia (\#H1460638584959).
}

RESUMO I Objetivo: Medir as alterações do músculo ciliar anterior durante a acomodação nos setores nasal, superior, temporal e inferior, através de um tomógrafo de coerência óptica de câmara anterior, e correlacioná-las com alterações de vergência. Métodos: Vinte e quatro indivíduos com olhos saudáveis e fácicos, com idade média de 27,1 $\pm 8,9$ anos, foram submetidos à medida com um tomógrafo de coerência óptica de câmara anterior. O músculo ciliar anterior foi medido nos setores nasal, temporal, superior e inferior para $0,-1,-2$ e -3D de vergência. Um modelo linear foi utilizado para avaliar a correlação de cada parâmetro do olho com a demanda acomodativa. Resultados: A área do músculo ciliar anterior aumentou significativamente com a acomodação em cada setor, com um aumento máximo foi de cerca de $30 \%$ para os setores naso-temporais, e cerca de $25 \%$ para os inferiores-temporais. O modelo linear mostrou uma tendência para uma relação positiva entre a alteração da área do músculo ciliar de cada setor e a vergência. Conclusão: A área do músculo ciliar anterior tende a aumentar com a acomodação, embora o aumento tenha se mostrado simétrico entre os setores superior-nasal e inferior-temporal. Estes resultados podem ajudar a aumentar a compreensão da biometria e biomecânica da acomodação.

Descritores: Acomodação ocular; Biometria; Músculo ciliar; Tomografia de coerência óptica; Presbiopia

\section{INTRODUCTION}

Information about the behavior of the ciliary muscle was first derived from histological studies performed postmortem in monkeys ${ }^{(1)}$, in particular in rhesus monkeys, because of similarities in the accommodative structures $^{(1)}$, mechanisms ${ }^{(2)}$, and development of presbyopia relative to time $\operatorname{scales}^{(3)}$. Later, this kind of information was obtained not only from monkeys, but also from human eyes. The studies revealed asymmetries between the nasal and temporal sectors ${ }^{(4)}$, as well as the ability of the ciliary muscle to contract throughout life $\mathrm{e}^{(5)}$. 
The advent of high-resolution equipment, such as ultrasound biomicroscopy (UBM) and optical coherence tomography (OCT), has allowed in vivo visualization of the anterior eye segment and in vivo study of changes in the anterior segment during accommodation ${ }^{(6)}$. Although the ciliary muscle is probably the most difficult structure to visualize, the UBM and OCT systems have enabled the study of this structure. In particular, studies have assessed differences in the diameter of the ciliary muscle in phakic and pseudophakic eyes ${ }^{(7)}$, morphologic changes in the ciliary body with accommodation in children and young adults ${ }^{(8-12)}$, and the effect of phenylephrine on the ciliary muscle ${ }^{(13)}$. These studies have reported differences in ciliary muscle morphology between young and adult eyes, although these differences have not been shown to affect the ability of the ciliary muscle to accommodate ${ }^{(12)}$. In addition to these results, it should be borne in mind that most studies assessed changes in the nasal and temporal ciliary muscle ${ }^{(8,9,14,15)}$ or only in the nasal ${ }^{(16)}$ or temporal sections ${ }^{(10,11,13)}$. Nonetheless, there is no in vivo evidence of changes in the superior and inferior ciliary muscle during accommodation.

The aim of the present study was to assess changes in the area of the ciliary muscle in four different sectors during accommodation. The results could help to increase understanding of accommodation biometry and biomechanics. Nevertheless, it should be taken into account that the participant's age was not taken into account for the analysis, and only changes in the anterior ciliary muscle were measured.

\section{METHODS}

\section{Patients}

The present study included 24 subjects with healthy, phakic eyes. Users of contact lenses were instructed not to wear them for at least 3 hours before the examination session. Because of the similarity between the eyes in healthy populations, only one eye per participant was measured, since measuring both eyes would simply double the number of data points providing the same information as one eye ${ }^{(17)}$. Donder's method was used to ensure that each patient had at least 3D of accommodation monocularly, and all measurements were taken during the same session.

The Universidad de Valencia Ethics Committee gave ethical approval, and the study was performed in adherence to the tenets of the Declaration of Helsinki. All patients provided written informed consent after the nature and possible consequences of the study had been explained to them.

\section{Optical coherence tomography}

All measurements were taken with the Visante Omni (Carl Zeiss AG, Oberkochen, Germany). This is a noncontact anterior segment OCT that acquires and analyzes detailed cross-sectional tomographic images. This system combines OCT technology with Placido disk topography to obtain measurements of both the cornea and the anterior segment, using infrared light of $1310 \mathrm{~nm}$. The vergence of the fixation target can be adjusted through a set of internal lenses, which were used to evaluate changes in the anterior eye with accommodation.

\section{Experimental procedure}

All measurements were taken in the laboratory of the Grupo de Investigación en Optometría (University of Valencia, Spain), and a skilled operator acquired all measurements on one eye of each subject. The ambient lighting conditions were kept stable during the whole procedure to avoid any significant variations in pupil diameter.

All measurements were taken from $0 \mathrm{D}$, which corresponds to the patient's far point, to -3 $\mathrm{D}$ of vergence in 1-D steps, and the order of each vergence was selected randomly. Each acquisition was performed 4 seconds after the subject's last blink to achieve a proper tear film spread over the cornea ${ }^{(18)}$. The Raw Image HR mode, which takes $512 \mathrm{~A}$-scans and represents a total area $10 \mathrm{~mm}$ in width and $3 \mathrm{~mm}$ in depth, was used to capture images of the anterior ciliary muscle at the nasal, temporal, inferior, and superior sectors. Some patients could not undergo scanning at the superior sector due to anatomical restrictions.

\section{Ciliary muscle analysis}

Image J software was used to measure the area of the ciliary muscle in each image (Figure 1A-D). The original image was converted into an 8-bit image (Figure 1A). Then the whole image was smoothed (Figure 1B), and the contrast was enhanced with a nonlinear histogram equalization (Figure 1C) to highlight different areas and borders. Then, the observer roughly delimited the area of the anterior ciliary muscle using two lines. One line was along the border between the sclera and the ciliary muscle, while the other line went through the scleral spur and was perpendicular to the first line. An automatic selecting tool was applied to select the area of the anterior ciliary muscle (Figure 1D), and the area was 
calculated. Figure 2 shows a representative example of the area of interest of the anterior ciliary muscle section.

\section{Statistical analysis}

The results were evaluated using SPSS software v.22 (IBM, Armonk, NY, USA). Repeated-measures analysis of variance (rANOVA) was performed to reveal significant differences among vergence conditions for each of the parameters measured with the device. Normality of all data sets was evaluated by the Shapiro-Wilk test. The

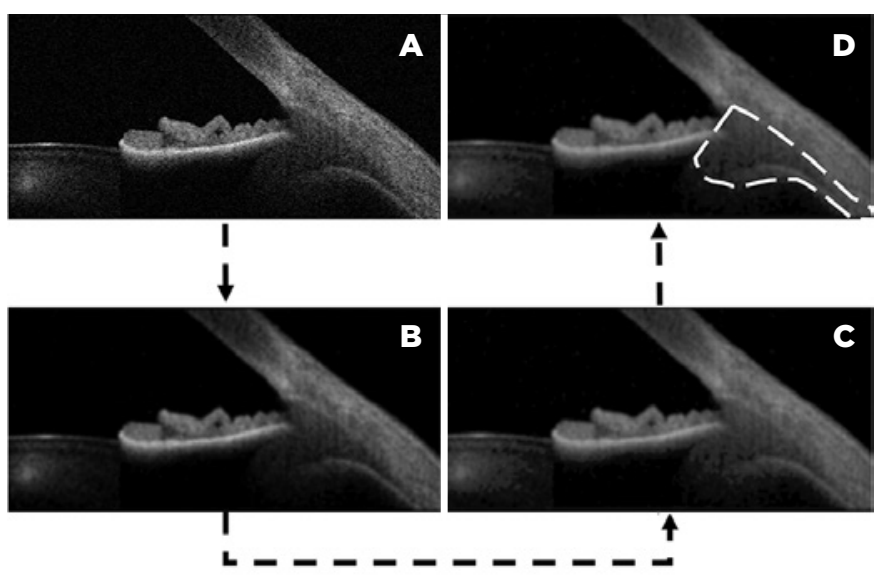

Figure 1. Representative images showing the procedure followed in the semiautomatic algorithm to analyze the anterior ciliary muscle area.
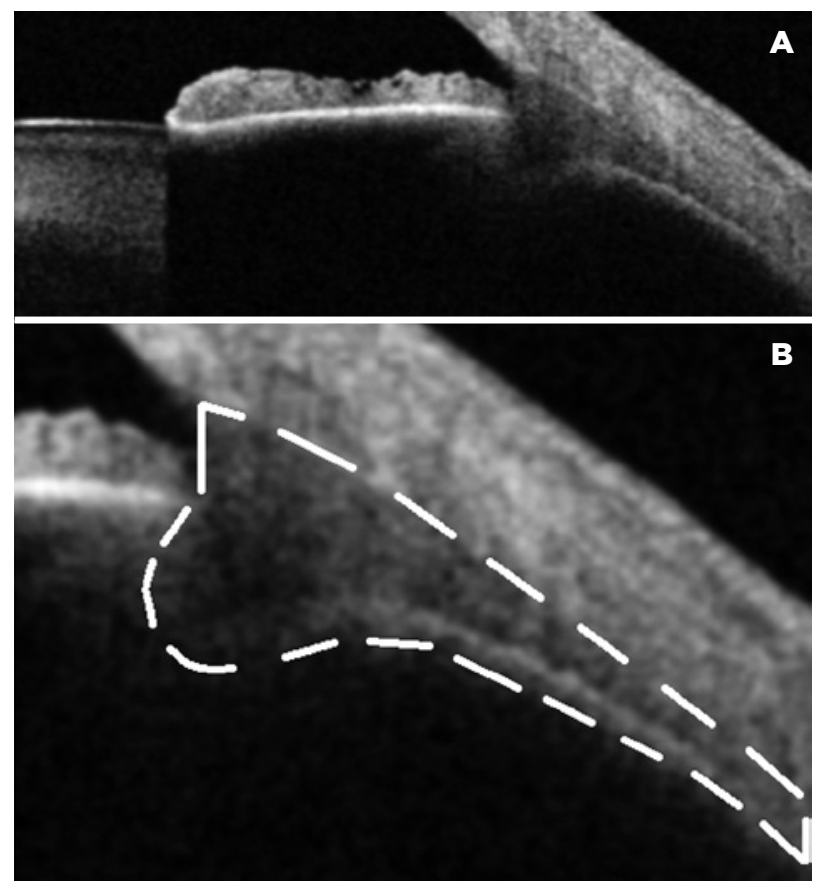

Figure 2. An example of an anterior ciliary muscle section ( $A$ ) and the area of interest for the analysis within white lines (B).
ANOVA procedure based on the $F$ statistic is robust under the breach of the normality assumption, provided that the data samples have no important asymmetries or similar distribution shapes ${ }^{(19)}$. Prior to rANOVA, the sphericity assumption was checked using Mauchly's sphericity test. The Greenhouse-Geisser correction was applied to those cases in which the result of the sphericity test was statistically significant ${ }^{(20)}$. The Bonferroni procedure was used as a post hoc test for comparisons between data groups when rANOVA revealed significant differences between measurements. This method allows the significance level for paired differences between the individual conditions to be obtained. In addition, the data corresponding to the median values for all vergence conditions were fitted to a linear model using Matlab 2015b (MathWorks, Natick, MA, USA) to describe the relationship between the dependent variable (change in anterior ciliary muscle area) and the independent variable (each accommodative stimulus). For each regression analysis, the intercept, slope, and determination coefficient were obtained. The coefficient of determination $\left(R^{2}\right)$ was used to assess how well the regression model fit the data, which can be interpreted as the proportion of the variance in the dependent variable that is predicted from the independent variable ${ }^{(21)}$. An additional analysis of covariance (ANCOVA) was performed to determine whether the slopes of the different parameters were different. A $p$-value less than 0.05 was considered to indicate statistical significance.

\section{RESULTS}

A total of 24 eyes from 24 subjects $(63 \%$ men and $37 \%$ women) were included in the study. The mean age of the subjects was $27.1 \pm 8.9$ years (range, 20 to 44 years), and the average spherical equivalent was $-1.02 \pm 2.41 \mathrm{D}$ (range, -6.75 to $3.25 \mathrm{D}$ ).

\section{Intrasector changes}

Figure 3 shows the changes in anterior ciliary muscle area during accommodation relative to the relaxed condition in the nasal (Figure 3A), temporal (Figure 3B), superior (Figure $3 C$ ), and inferior (Figure 3D) sectors. This figure shows that the larger the vergence, the greater the change in ciliary muscle area.

The median relative change in nasal ciliary muscle area (Figure $3 \mathrm{~A}$ ) was $12 \%$ at 1D of accommodation, 23\% at $2 \mathrm{D}$, and $30 \%$ at $3 \mathrm{D}$; all differences among vergences were statistically significant $(p<0.001)$. The maximum 

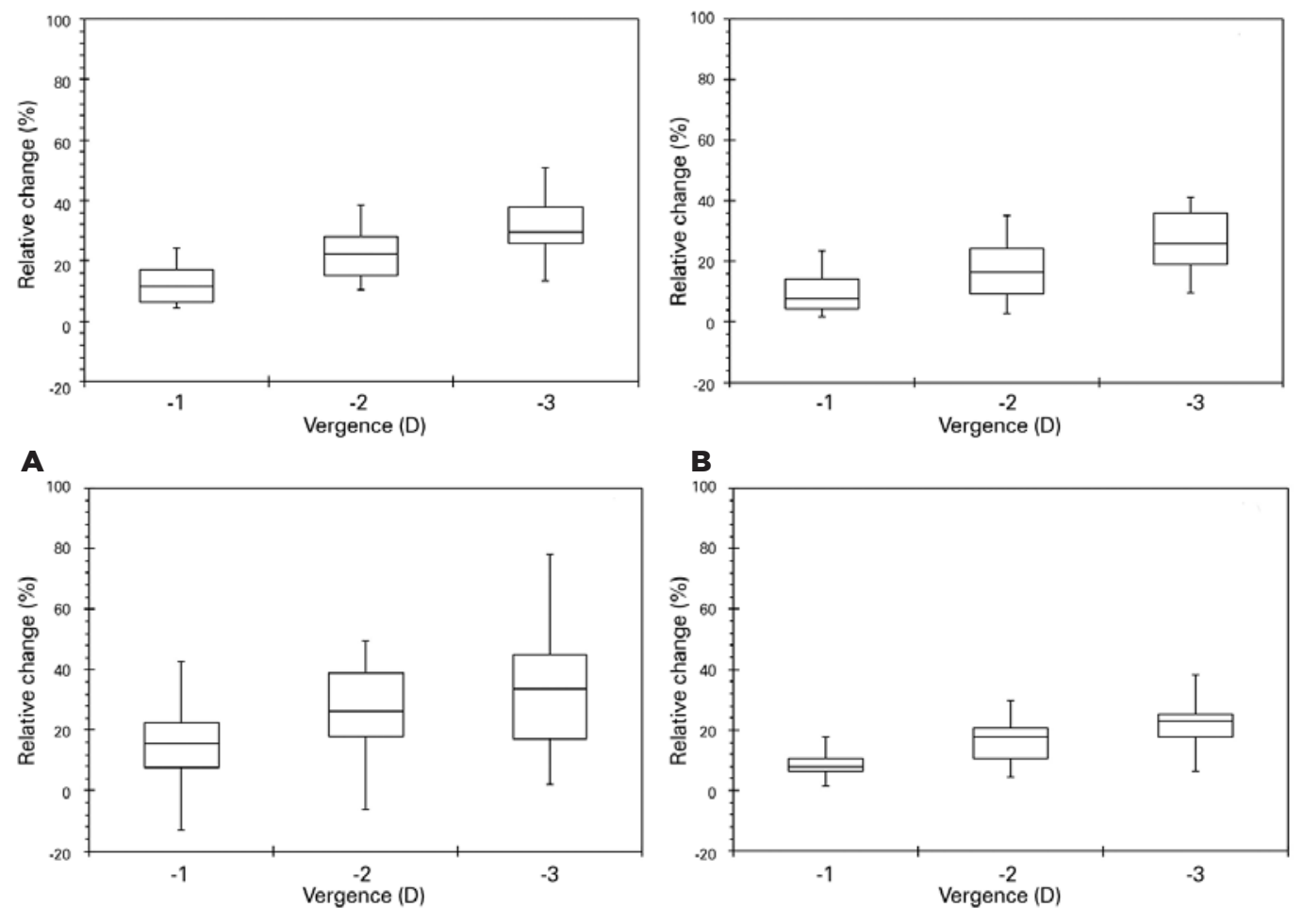

C

D

Figure 3. Box-and-whisker plots of relative changes in ciliary muscle area for the nasal (A), temporal (B), superior (C), and inferior (D) sectors.
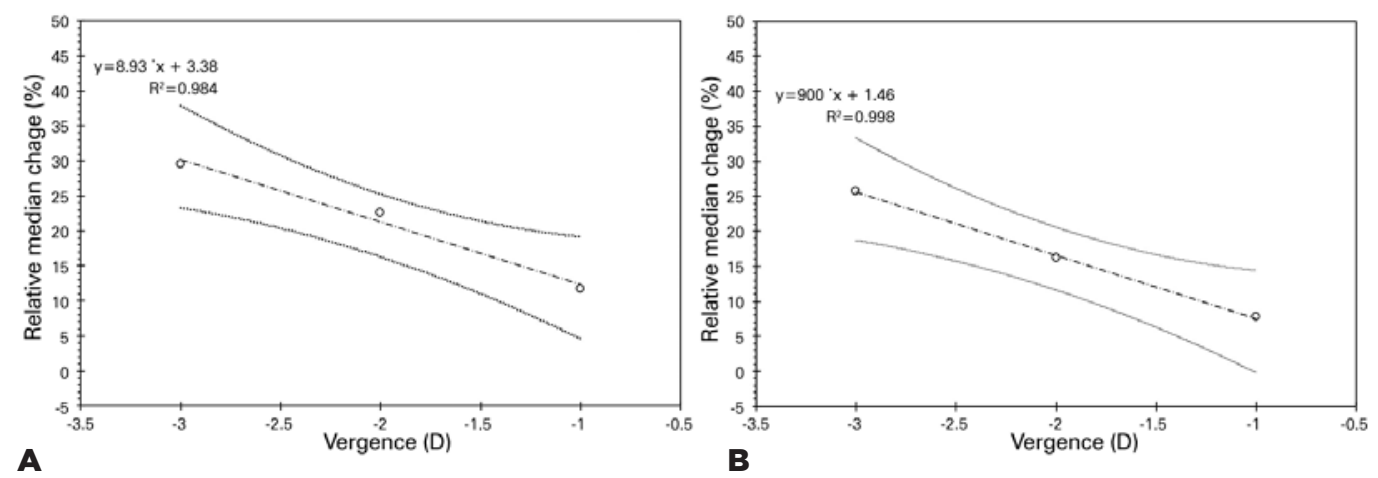

A
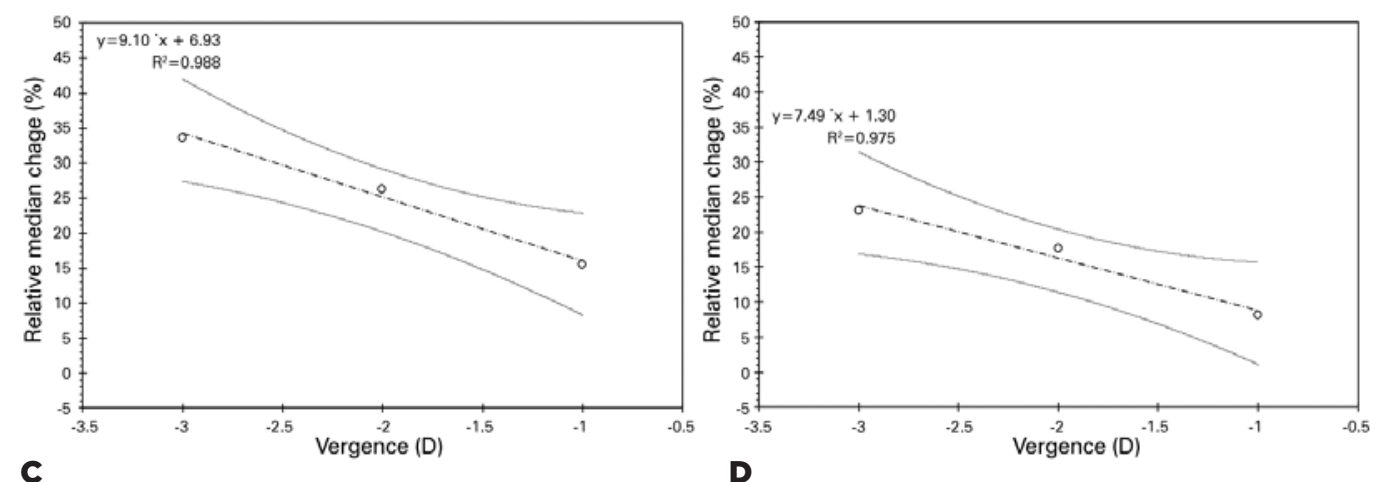

Figure 4. Linear regression between the median change in ciliary muscle area and the vergence for the nasal (A), temporal (B), superior (C), and inferior (D) sectors. The small circles represent the median change obtained at each vergence, the dashed-dotted line represents the linear fit model, and the two external dashed lines represent the $95 \%$ confidence intervals of the estimates. 
Table 1. Percentage relative change in area with respect to the unaccommodated eye of four anterior ciliary muscle sectors with 1D, 2D, and 3D of accommodation

\begin{tabular}{lccc}
\hline Sector & 1D $\%$ & 2D \% & 3D\% \\
\hline Nasal & 12 & 23 & 30 \\
Temporal & 8 & 16 & 26 \\
Superior & 14 & 26 & 31 \\
Inferior & 8 & 18 & 23 \\
\hline
\end{tabular}

vergence $(-3 \mathrm{D})$ resulted in the largest variability in the nasal ciliary muscle area, which was smaller than $40 \%$. On the other hand, the median temporal ciliary muscle area (Figure $3 \mathrm{~B}$ ) was $8 \%$ at $1 \mathrm{D}, 16 \%$ at $2 \mathrm{D}$, and $26 \%$ at $3 \mathrm{D}$; all differences among vergences were statistically significant $(p<0.001)$. Additionally, the results showed that the lower the vergence, the smaller the variability.

Figure 3C shows changes in the superior ciliary muscle area. The median change was $14 \%$ at $1 \mathrm{D}, 26 \%$ at $2 \mathrm{D}$, and $31 \%$ at $3 \mathrm{D}$; statistically significant differences were only obtained between $-1 \mathrm{D}$ and $-2 \mathrm{D}$ of vergence $(p=0.001)$ and between $-1 D$ and -3 D of vergence $(p=0.032)$. Similarly, the inferior ciliary muscle area (Figure 3D) increased by $8 \%$ at $-1 \mathrm{D}$ of vergence, $18 \%$ at $-2 \mathrm{D}$, and $23 \%$ at $-3 \mathrm{D}$; all differences between vergences were statistically significant $(p<0.001)$. In both sectors, the results showed that the smaller the vergence, the smaller the dispersion obtained in the results. Table 1 summarizes the relative changes in area with respect to the unaccommodated state for all sectors with $1 \mathrm{D}, 2 \mathrm{D}$, and $3 \mathrm{D}$ of accommodation.

\section{Intersector changes}

Figure 4 shows the linear regression between the median change in ciliary muscle area and vergence for the nasal (Figure 4A), temporal (Figure 4B), superior (Figure $4 C$ ), and inferior (Figure 4D) sectors. In each panel, the small circles represent the median change obtained at each vergence, the dashed-dotted line represents the linear fit model, and the two external dashed lines represent the 95\% confidence intervals of the estimates.

As was expected, the linear models showed a tendency toward a positive association between the change in ciliary muscle area and the vergence for each ciliary muscle sector, and the coefficient of determination was in all cases greater than 0.97 . The superior sector had the steepest slope (Figure 4C), while the inferior sector had the flattest slope (Figure 4D). The nasal, temporal, and superior sectors had similar slopes (Figure 4A-C), and ANCOVA revealed that the slopes for the changes in the anterior ciliary muscle area with vergence for the different sectors were not significantly different from each other ( $p>0.50$ for all comparisons).

\section{DISCUSSION}

The aim of the present study was to assess changes in anterior ciliary muscle area at different sectors during accommodation and correlate them with vergence by means of an anterior chamber OCT. The results could help to increase the current understanding of accommodation biometry and biomechanics.

The ciliary muscle area of each sector tended to increase with the vergence (Figure 3A-D). The maximum median increase in ciliary muscle area at $-3 \mathrm{D}$ of vergence was less than $40 \%$ for all sectors analyzed. Linear regression showed a tendency toward a positive association between changes in anterior ciliary muscle area and vergence for each muscle sector (Figure 4A-D). That is, the larger the vergence, the larger the change in anterior ciliary muscle area. These results agree with those of previous studies assessing changes in the ciliary muscle with vergence $\mathrm{e}^{(8,10,11)}$. One study analyzed ciliary muscle morphology with an anterior segment OCT in 50 pre-presbyopic subjects ${ }^{(8)}$. In that study, the ciliary muscle was assessed in terms of anterior length and width at $25 \%, 50 \%$, and $75 \%$ of the total length posterior to the scleral spur in the temporal and nasal sectors. The results showed that the anterior portion of the ciliary muscle thickened with accommodation. Another study assessed changes in the morphology of the ciliary muscle with vergence in 30 children in terms of thickness at 1, 2, and $3 \mathrm{~mm}$ behind the scleral spur and at the maximum point ${ }^{(10)}$. The study measured the temporal ciliary muscle with an anterior segment OCT at three vergences $(0,-4$, and -6 D). The results showed that during accommodation, the temporal ciliary muscle increased at $1 \mathrm{~mm}$ and at the maximum point, before thinning at $3 \mathrm{~mm}$. Similarly, another study developed a measurement protocol to assess changes in the shape and size of the temporal ciliary muscle during accommodation with an anterior segment $\mathrm{OCT}^{(11)}$. That study included 25 adults and ciliary muscle thickness was measured at 1,2, and $3 \mathrm{~mm}$ posterior to the scleral spur as well as at the point of maximum thickness, for distance vision and 4D of accommodation. The results showed that temporal ciliary muscle thickness increased 
at the maximum point and at $1 \mathrm{~mm}$ behind the scleral spur and thinned at $3 \mathrm{~mm}$ from the scleral spur.

In addition to these results, these studies reported a large variability between subjects in the response of the central part of the ciliary body during accommodation $^{(8,10,11)}$, which thickened in some subjects and thinned in others. This area has been shown to have a lack of interaction between accommodative responses and ciliary muscle thickness, because the thinnest muscles behaved in an identical manner to the thicker ones $^{(8)}$. Further studies should aim to assess changes in the central ciliary muscle with vergence in detail.

The results showed that the larger the vergence, the larger the dispersion, which could be expected from a physiological point of view due to the effect of microfluctuations ${ }^{(22)}$. Accommodation fluctuates over a range of about $\pm 0.5 \mathrm{D}$ from the focus point ${ }^{(23)}$, and the fluctuations tend to increase with accommodation. It is not clear whether the greatest level of fluctuations is found at the near point or at intermediate distances ${ }^{(22)}$.

The maximum median increase in ciliary muscle area was about $30 \%$ for the nasal and superior sectors (Figure $3 \mathrm{~A}$ and $\mathrm{C}$ ) and about $25 \%$ for the inferior and temporal sectors (Figure $3 \mathrm{~B}$ and $\mathrm{D}$ ). According to these results, the changes in ciliary muscle area during accommodation are symmetric between the pair sectors superior-nasal and inferior-temporal. A previous in vivo study compared changes in nasal and temporal ciliary muscle morphology during accommodation and found that the temporal sector was thicker and showed a greater contractile response ${ }^{(8)}$. The results of the present study are in agreement with these findings. They report new evidence for the sectorial response of the ciliary muscle and add new measurements of two sectors in the vertical meridian that were not included previously. Nevertheless, it should be taken into account that an in vitro study investigated histological meridional sections in 85 melanoma eyes and 10 eyes from normal donors $^{(24)}$. The study found no statistically significant differences within the nasal and temporal sectors, within the superior and inferior sectors, or between the horizontal and vertical meridians.

The present study assessed sectorial changes in ciliary muscle area without taking into account the age effect. Age plays a significant role in accommodation, and further studies should assess sectorial changes in the ciliary muscle as a function of age. Since there is no easily identifiable landmark to assist in the alignment of ciliary muscle images, the observer in the present study did his best to align the scan beam with the midpoint of the pupil. Furthermore, it should be borne in mind that the present study only assessed changes in the anterior ciliary muscle, due to the small field of view of the anterior segment OCT used.

In summary, the nasal, temporal, superior, and inferior sectors of the anterior ciliary muscle seem to increase during accommodation, although these changes are symmetric between the pair of sectors superior-nasal and inferior-temporal. To know the real effects of accommodation in the biomechanics of the eye could be useful for the design of optical systems to complement the loss of accommodation, maintaining the crystalline lens or replacing it, when presbyopia occurs.

\section{REFERENCES}

1. Koretz JF, Bertasso AM, Neider MW, True-Gabelt BA, Kaufman PL. Slit-lamp studies of the rhesus monkey eye: ll. Changes in crystalline lens shape, thickness and position during accommodation and aging. Exp Eye Res. 1987;45(2):317-26.

2. Glasser A, Kaufman PL. The mechanism of accommodation in primates. Ophthalmology. 1999;106(5):863-72.

3. Kaufman PL, Bito LZ, DeRousseau C). The development of presbyopia in primates. Trans Ophthalmol Soc U K. 1982;102(3):323-6.

4. Aiello AL, Tran VT, Rao NA. Postnatal development of the ciliary body and pars plana. A morphometric study in childhood. Arch Ophthalmol. 1992;110(6):802-5.

5. Pardue MT, Sivak JG. Age-related changes in human ciliary muscle. Optom Vis Sci. 2000;77(4):204-10.

6. Neri A, Ruggeri M, Protti A, Leaci R, Gandolfi SA, Macaluso C. Dynamic imaging of accommodation by swept-source anterior segment optical coherence tomography. J Cataract Refract Surg. 2015;41(3):501-10.

7. Strenk SA, Strenk LM, Guo S. Magnetic resonance imaging of aging, accommodating, phakic, and pseudophakic ciliary muscle diameters. J Cataract Refract Surg. 2006;32(11):1792-8.

8. Sheppard AL, Davies LN. In vivo analysis of ciliary muscle morphologic changes with accommodation and axial ametropia. Invest Ophthalmol Vis Sci. 2010;51(12):6882-9.

9. Sheppard AL, Davies LN. The effect of ageing on in vivo human ciliary muscle morphology and contractility. Invest Ophthalmol Vis Sci. 2011;52(3):1809-16.

10. Lewis HA, Kao CY, Sinnott LT, Bailey MD. Changes in ciliary muscle thickness during accommodation in children. Optom Vis Sci. 2012;89(5):727-37.

11. Lossing LA, Sinnott LT, Kao CY, Richdale K, Bailey MD. Measuring changes in ciliary muscle thickness with accommodation in young adults. Optom Vis Sci. 2012;89(5):719-26.

12. Tabernero J, Chirre E, Hervella L, Prieto P, Artal P. The accommodative ciliary muscle function is preserved in older humans. Sci Rep. 2016;6(1):25551.

13. Richdale K, Bailey MD, Sinnott LT, Kao CY, Zadnik K, Bullimore MA. The effect of phenylephrine on the ciliary muscle and accommodation. Optom Vis Sci. 2012;89(10):1507-11.

14. Croft MA, McDonald JP, Katz A, Lin TL, Lütjen-Drecoll E, Kaufman PL. Extralenticular and lenticular aspects of accommodation and presbyopia in human versus monkey eyes. Invest Ophthalmol Vis Sci. 2013;54(7):5035-48. 
15. Croft MA, Nork TM, McDonald JP, Katz A, Lütjen-Drecoll E, Kaufman PL. Accommodative movements of the vitreous membrane, choroid, and sclera in young and presbyopic human and nonhuman primate eyes. Invest Ophthalmol Vis Sci. 2013;54(7):5049-58.

16. Kao CY, Richdale K, Sinnott LT, Grillott LE, Bailey MD. Semiautomatic extraction algorithm for images of the ciliary muscle. Optom Vis Sci. 2011;88(2):275-89.

17. McAlinden C, Khadka J, Pesudovs K. Statistical methods for conducting agreement (comparison of clinical tests) and precision (repeatability or reproducibility) studies in optometry and ophthalmology. Ophthalmic Physiol Opt. 2011;31(4):330-8.

18. Montés-Micó R, Alió JL, Muñoz G, Charman WN. Temporal changes in optical quality of air-tear film interface at anterior cornea after blink. Invest Ophthalmol Vis Sci. 2004;45(6):1752-7.

19. Tan W. Sampling distributions and robustness of $t, F$ and variance-ratio in two samples and ANOVA models with respect to departure from normality. Commun Stat Theory Methods. 1982;11:486-511.
20. Box G. Some theorems on quadratic forms applied in the study of analysis of variance problems. Il: effects of inequality of variance and of correlation between errors in the two-way classification. Ann Math Stat. 1954;25(3):484-98.

21. Mendenhall W, Beaver R, Beaver B. Linear regression and correlation. In: Julet $M$, editor. Introduction to probability and statistics. Boston, USA: Cengage Learning; 2013.

22. Charman WN, Heron G. Microfluctuations in accommodation: an update on their characteristics and possible role. Ophthalmic Physiol Opt. 2015;35(5):476-99.

23. Collins G. The electronic refractionometer. Br J Physiol Opt. 1937; 11:30-42.

24. Tamm S, Tamm E, Rohen JW. Age-related changes of the human ciliary muscle. A quantitative morphometric study. Mech Ageing Dev. 1992;62(2):209-21. 